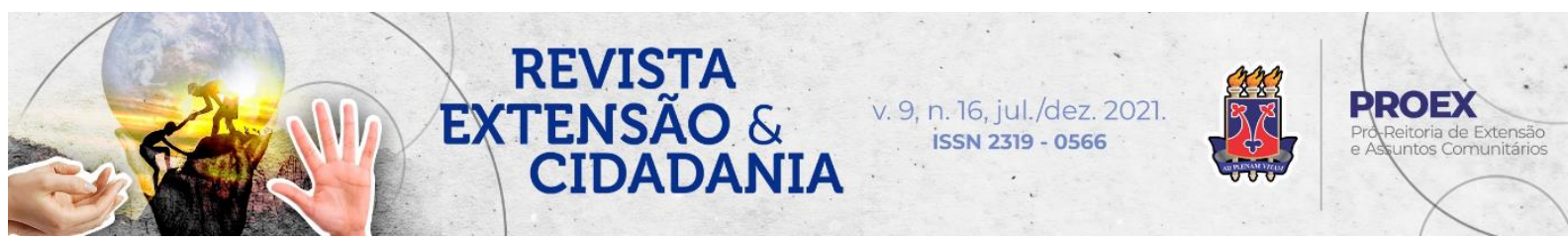

DOI: 10.22481/recuesb.v9i16.9049

\title{
CICLO DE SEMINÁRIOS EM QUÍMICA DOS DIVERSOS SABERES - UESB: UM RELATO DE EXPERIÊNCIA DURANTE A PANDEMIA
}

\section{CYCLE OF SEMINARS IN DIVERSE KNOWLEDGE CHEMISTRY - UESB: A REPORT OF EXPERIENCE DURING THE PANDEMIC}

\section{CICLO DE SEMINARIOS DE QUÍMICA DEL CONOCIMIENTO DIVERSO - UESB: INFORME DE EXPERIENCIA DURANTE LA PANDEMIA}

Robson Almeida Silva ${ }^{1}$

Mariele Moraes Brito ${ }^{2}$

Geisa Sales Oliveira ${ }^{3}$

Neiane Oliveira Sampaio ${ }^{4}$

Amanda Pereira Santos 5

Fabiany Cruz Gonzaga ${ }^{6}$

Resumo: A pandemia da Covid-19, declarada em março de 2020 pela Organização Mundial da Saúde, fez com que o mundo inteiro voltasse sua atenção ao contágio do novo coronavírus. Universidades e demais meios educativos tiveram de buscar por alternativas digitais para o prosseguimento de suas atividades no intuito de evitar a propagação da Covid-19. Nessa condição se impossibilitou a realização do projeto "I Ciclo de Seminários de Química dos Diversos Saberes" de forma presencial, então optou-se pelo caminho remoto. Objetivos: Divulgar diversas palestras sob diferentes áreas da química e sua contribuição na ciência e no desenvolvimento social. Metodologia: Trata-se de um relato de experiência de ações

\footnotetext{
${ }^{1}$ Bolsista de Iniciação Científica, do Conselho Nacional de Desenvolvimento Científico e Tecnológico (CNPq); Graduando em Química com Atribuições Tecnológicas, pela Universidade Estadual do Sudoeste da Bahia (UESB), Campus de Vitória da Conquista, Bahia, Brasil. Orcid: https://orcid.org/0000-0002-9808-1691 E-mail: 201810186@uesb.edu.br

${ }^{2}$ Licencianda em Química, pela Universidade Estadual do Sudoeste da Bahia (UESB), Campus de Vitória da Conquista, Bahia, Brasil. Orcid: https://orcid.org/0000-0002-1568-8755 E-mail: 201411073@uesb.edu.br

${ }^{3}$ Licencianda em Química, pela Universidade Estadual do Sudoeste da Bahia (UESB), Campus de Vitória da Conquista, Bahia, Brasil. Orcid: https://orcid.org/0000-0002-6941-3458 E-mail: 201710972@uesb.edu.br

${ }^{4}$ Licencianda em Química, pela Universidade Estadual do Sudoeste da Bahia (UESB), Campus de Vitória da Conquista, Bahia, Brasil. Orcid: https://orcid.org/0000-0003-1951-5285 E-mail: 201610396@uesb.edu.br

${ }^{5}$ Licencianda em Química, pela Universidade Estadual do Sudoeste da Bahia (UESB), Campus de Vitória da Conquista, Bahia, Brasil. Orcid: https://orcid.org/0000-0001-5927-5613 E-mail: 201410540@uesb.edu.br

${ }^{6}$ Docente do Departamento de Ciências Exatas e Naturais, da Universidade Estadual do Sudoeste da Bahia (UESB), Campus de Vitória da Conquista, Bahia, Brasil. Orcid: https://orcid.org/0000-0001-5801-6038 E-mail: fabianycruz@uesb.edu.br
} 
desenvolvidas na modalidade de extensão durante a pandemia da SARS-CoV-2 realizada em plataforma virtual (Streamyard, Youtube). Resultados: A participação da comunidade externa foi significativa na execução do projeto de extensão. O projeto ocorreu com uma intensiva participação de discentes de ensino médio e de ensino superior. O projeto se deu de forma interdisciplinar agregando participantes de diversas áreas do conhecimento tendo como majoritariedade as grandes áreas das Ciências Exatas e da Terra. Conclusão: O projeto de extensão proporcionou uma integração, além dos muros da universidade, promovendo a inserção da comunidade interna e externa e a ajudando-as compreender e promover possibilidades de colaborações científicas.

Palavras-chave: Educação Científica. Extensão. Seminários. Pandemia.

Abstract: The Covid-19 pandemic declared in March 2020 by the World Health Organization made the whole world turn its attention to the contagion of the new coronavirus. Universities and other educational means had to seek digital alternatives for the continuation of their activities to prevent the spread of Covid-19, and given the impossibility of the project "I Cycle of Chemistry Seminars of Diverse Knowledge" to occur in person, the remote path was chosen. Objectives: Disseminate several lectures in different areas of chemistry and their contribution to science and social development. Methodology: This is an experience report of actions developed in an extensionist manner during the SARS-CoV-2 pandemic carried out on a virtual platform (Streamyard, Youtube), following guidelines from health authorities. Results: The participation of the external community was significant in the execution of the extension project. The project took place with the intensive participation of high school and higher education students. The project took place in an interdisciplinary way, bringing together participants from different areas of knowledge, with the majority of the major areas of Exact and Earth Sciences. Conclusion: Therefore, the extension project provided an integration beyond the university walls, promoting the integration of the internal and external community and helping them to understand and promote scientific collaborations.

Keywords: Scientific Education. Extension. Seminars. Pandemic.

Resumen: La pandemia Covid-19 declarada en marzo de 2020 por la Organización Mundial de la Salud hizo que el mundo entero volviera su atención hacia las situaciones de contagio del nuevo coronavirus. Las universidades y otros entornos educativos tuvieron que buscar alternativas digitales para continuar con sus actividades. En esta condición, se llevó a cabo de manera no presencial el proyecto de extensión "I Ciclo de Seminarios sobre Química de los Conocimientos Diversos". Este artículo tiene como objetivo reportar la experiencia de realizar este evento de forma remota, evaluando el alcance de la actividad en términos de público objetivo en una plataforma virtual (Streamyard®, Youtube®). Se pudo identificar que la participación de la comunidad externa fue significativa. El proyecto se llevó a cabo con una participación intensiva de estudiantes de bachillerato, educación superior y de manera interdisciplinaria, reuniendo participantes de diferentes áreas del conocimiento, con la participación mayoritaria de personas de amplias áreas de las Ciencias Exactas y de la Tierra. El proyecto de extensión brindó una integración más allá de los muros universitarios, promoviendo la interacción de la comunidad interna y externa y ayudándoles a comprender y promover las posibilidades de colaboración científica. Por lo tanto, a pesar de la distancia social que impuso la pandemia, la realización de eventos remotos resultó ser una herramienta positiva para mantener las actividades de extensión de la Universidad.

Keywords: Educación científica. Extensión. Seminarios Pandemia.

Revista Extensão \& Cidadania, v. 9, n. 16, p.123-135, jul./dez. 2021.

ISSN 2319-0566 DOI: 10.22481/recuesb.v9i16.9049 


\section{Introdução}

Há algum tempo pesquisadores de doenças de infectocontagiosas indicam a possibilidade de novas pandemias. Segundo eles, não é uma questão de "se" e sim de "quando" irá acontecer (WOLFE, 2011). Esse cenário se apresenta hoje, onde o mundo vive a maior crise sanitária já registrada, o mês era dezembro e o ano 2019, quando na China, em uma cidade da província de Hubei, chamada Wuhan, desencadeou-se um surto de pneumonia, cujo agente foi classificado como SARS-CoV-2 e a nova infecção nomeada por Covid-19.

Por volta de 5 de março de 2020, já havia cerca de 80.000 casos de Covid-19 na China e 16.000 outros distribuídos entre outros 87 países. Em 11 de março de 2020, a Organização Mundial da Saúde (OMS) declara a Covid-19 uma pandemia (OMS, 2020), cerca de três meses após o relato do primeiro caso na China, o vírus chegou ao Brasil. O primeiro caso da Covid19 foi confirmado em 26 de fevereiro de 2020 e o primeiro óbito em 17 de março do mesmo ano (BRASIL, 2020a).

A magnitude da pandemia da Covid-19 trouxe inúmeros problemas, incluindo os de ordem social e educacional. O isolamento social foi a medida adotada e aconselhada pela OMS, comunidade científica e diversos governos ao redor do mundo como principal recomendação em defesa e combate à disseminação do SARS-CoV-2 (OMS, 2020; BRASIL, 2020a).

Nesse contexto, a pandemia da Covid-19 trouxe um grande desafio para às universidades no que diz respeito a darem respostas à sociedade, e um caminho eficaz é por intermédio ações de extensão universitária. De acordo com Ciríaco et al. (2020), Nunes e Da Cruz Silva (2011), a extensão universitária é um processo educativo, cultural e científico que articula, de forma indissociável, o ensino e a pesquisa, e viabiliza uma relação mútua e transformadora entre a universidade e a sociedade. Assim sendo, extensão universitária desenvolve um papel fundamental na sociedade, visto que é uma forma de construir, disseminar e discutir o conhecimento produzido dentro das universidades mediante realidades e necessidades sociais do país.

O termo "extensão", no âmbito das Instituições de Ensino Superior (IES), teve origem na Legislação Educacional Nacional, em 1931, por intermédio do primeiro Estatuto das Universidades Brasileiras, que fazia referência ao oferecimento de cursos e conferências de caráter educacional como "organismo da vida social da Universidade" (SOUSA, 1995). Logo

Revista Extensão \& Cidadania, v. 9, n. 16, p.123-135, jul./dez. 2021. 
depois ressurgiu, no então texto da Lei $\mathrm{n}^{\circ}$ 5.540/68 tornando-o atividade de extensão obrigatória em todas as IES do Brasil (ARROYO; ROCHA, 2010).

A extensão universitária pode entender conjunturas sociais da comunidade, especialmente em seu entorno, e assim instaurar programas e projetos que possam contribuir para mudanças sociais de curto, médio e longo prazo. Dessa maneira, a extensão universitária tem como objetivo a produção de novos conhecimentos para desenvolver soluções diante de problemas atuais visando à transformação social, bem como uma diminuição da desigualdade nos setores mais vulneráveis da sociedade (DA SILVA et al., 2020).

Para além disso, ações extensionistas auxiliam na construção profissional e social dos estudantes de diversas áreas, contribuindo para que se tornem cidadãos e acima de tudo profissionais integrados com a conjuntura da comunidade ao seu redor na busca por novas alternativas para garantir uma melhor assistência e, consequentemente, indivíduos mais conscientes do seu papel transformador. Nesta perspectiva, a formação de um profissional cidadão é baseada nesta efetiva relação de reciprocidade do acadêmico com a comunidade, seja para se situar historicamente, para se identificar culturalmente ou para servir de referência para sua formação com os problemas que um dia terá que enfrentar (DA SILVA et al., 2020).

A localização e espaço favorável são elementos que corroboram para a execução das ações de extensão. De fato, as ações de extensão são realizadas em sua maioria em praças, parques, escolas/colégios, creches, associação de moradores, asilos, empresas, Unidades Básicas de Saúde; pontos estratégicos para o sucesso das ações e alcance amplo do públicoalvo (DA SILVA et al., 2020). Porém, com o advento da pandemia se questionou como fazer para realizar extensão universitária diante do isolamento social imposto pelo Covid-19. Essa indagação é importante e também preocupante, uma vez que, em 18 de março de 2020, em decorrência da Covid-19, o Ministério da Educação suspendeu as aulas presenciais em todo o Brasil, através da Portaria no 343, de 17 de março de 2020 (BRASIL, 2020b). Logo, articular e realizar novos mecanismos de atuação na extensão se fez imperativo.

As universidades do país precisaram suspender as atividades presenciais de ensino e algumas implementaram atividades remotas. Assim sendo, diante da necessidade do isolamento social e atividades presenciais nas universidades suspensas, muitos, senão todos os estudantes entraram em confinamento em suas casas, outros retornaram ao seu estado, cidade ou município.

Revista Extensão \& Cidadania, v. 9, n. 16, p.123-135, jul./dez. 2021. 
Diante disso, o Diretório Acadêmico dos cursos de Química, da Universidade Estadual do Sudoeste da Bahia (UESB), do campus de Itapetinga, realizou um webinário totalmente online utilizando ferramentas digitais. Neste, foram agregados saberes ligados à saúde, à engenharia, à alimentação, à agroecologia, à indústria, etc. Este artigo traz como objetivo fazer um relato de experiência de realização do "I Ciclo de Seminários de Química dos Diversos Saberes" de modo remoto, avaliando o alcance da atividade em função do público-alvo.

\section{Metodologia}

Trata-se de um estudo descritivo, que visa relatar ações do projeto "I Ciclo de Seminários de Química dos Diversos Saberes”. O projeto inicialmente foi aprovado pela PróReitoria de Extensão e Assuntos Comunitários (PROEX), da UESB, como um evento de caráter local, idealizado em 2020, pelo Diretório Acadêmico dos Cursos de Química (DAQUIM), da UESB, campus de Itapetinga. Ademais, o projeto foi composto por oito discentes de graduação em Química, além de uma docente orientadora.

Em decorrência da pandemia da Covid-19 e da necessidade de distanciamento social, foi feito um planejamento para a realização do evento de modo online. A elaboração do seminário se iniciou em julho de 2020, com reuniões semanais feitas através de dispositivos de videochamadas pela plataforma do Google Meet.

Os membros do DAQUIM foram responsáveis por procurar cada palestrante e mediadores de acordo com a temática proposta, além de promoverem uma intensa divulgação utilizando as tecnologias digitais. Nas reuniões foi decidido que o "I Ciclo de Seminários de Química dos Diversos Saberes" se iniciaria no dia 16 de agosto de 2020 e seu término em 16 de outubro de 2020, ocorrendo no período noturno duas vezes por semana nas quartas-feiras e aos sábados.

As inscrições foram abertas no final de agosto de 2020 e foram realizadas as inscrições dos participantes através da plataforma digital Even3®. Os meios de divulgação do seminário foram: Portal institucional; Página específica da ação no site da UESB; Redes sociais da UESB e do DAQUIM (Facebook, Instagram, Twitter, Whatsapp)®; E-mail institucional. Todas as postagens possuíram uma linguagem objetiva levando ao espectador uma oportunidade de receber informações precisas e acadêmicas sobre os diversos saberes da química.

Revista Extensão \& Cidadania, v. 9, n. 16, p.123-135, jul./dez. 2021. 
O evento foi realizado pela plataforma do Streamyard®, sendo as palestras transmitidas ao vivo pelo canal do evento no YouTube®. Antes de cada palestra, o mediador e o palestrante eram submetidos a um treinamento promovido pela comissão organizadora sobre como funcionava a plataforma digital.

\section{Resultados e discussão}

No decorrer de quatro meses da organização do Projeto de Extensão (julho, agosto, setembro e outubro de 2020), a comissão formada pelos membros do DAQUIM da UESB, campus Itapetinga, fomentou utilizar as ferramentas digitais que serviram como primordiais no processo de divulgação da agenda do evento, tendo-se difundindo em todo o país e também com ouvintes internacionais.

O "I Ciclo de Seminários de Química dos Diversos Saberes" foi realizado com diversas palestras de caráter interdisciplinar, apresentando também palestras relacionadas à temática da pandemia de Covid-19. O projeto procedeu-se de forma gratuita, ao todo, foram 14 seminários, com duração de duas horas, sendo realizado duas vezes por semana entre 14 de setembro a 16 de outubro de 2020.

Os temas foram apresentados por docentes de diversas universidades do país e exterior, profissionais e empresários do setor químico, além de serem mediados por mestrandos, doutorandos e docentes do Departamento de Ciências Exatas e Naturais e do Departamento de Tecnologia Rural e Animal, da UESB. Os principais assuntos tratados são descritos na Tabela 1, que está organizada na ordem de realização do evento:

Revista Extensão \& Cidadania, v. 9, n. 16, p.123-135, jul./dez. 2021. 


\section{Tabela 1 - Seminários abordados durante o Projeto de Extensão}

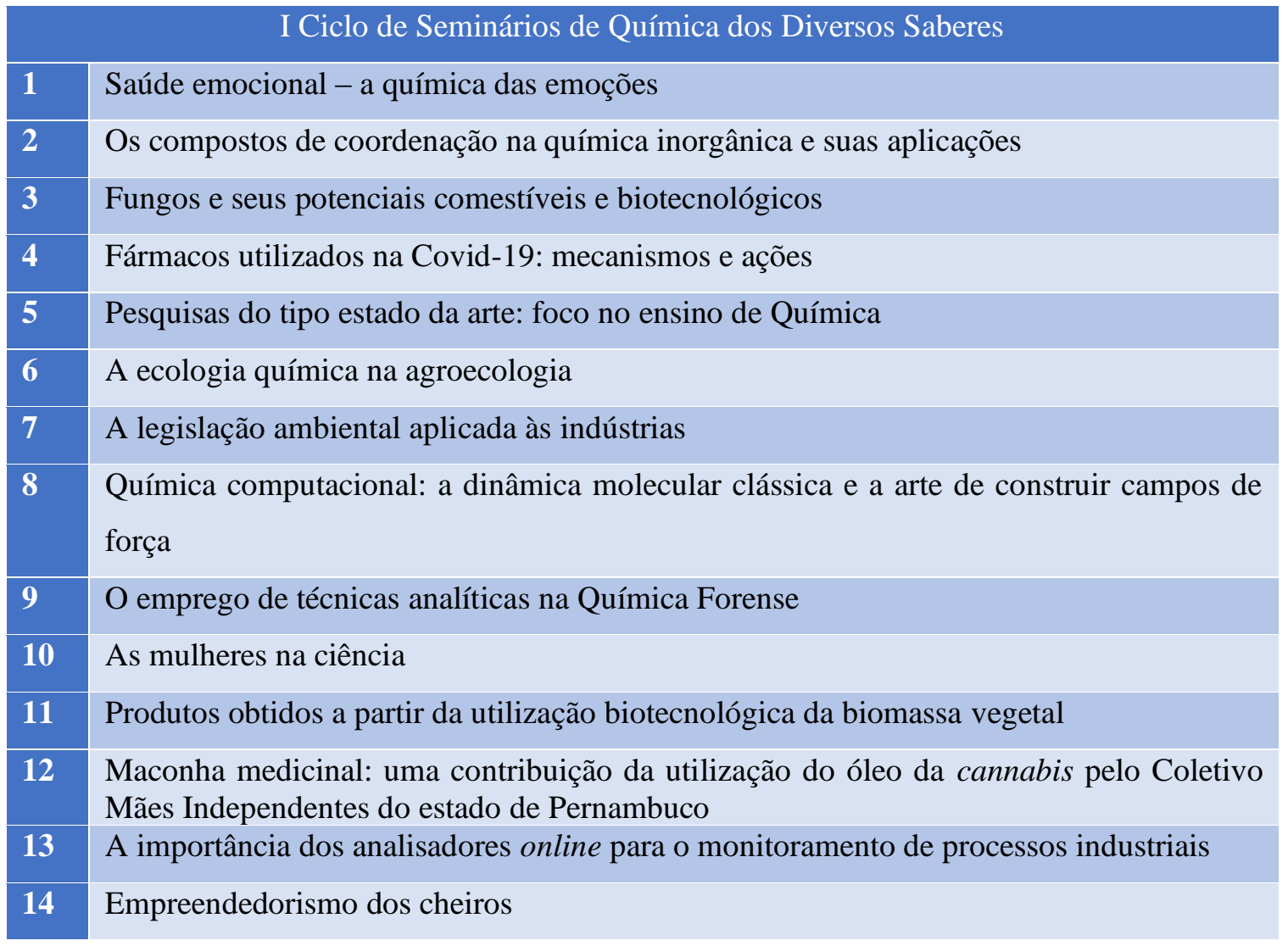

Fonte: Elaborado pelos Autores (2021).

Dentre as redes sociais que mais impulsionaram o Projeto de Extensão foi o Instagram ${ }^{\circledR}$ e a comunicação pelo Whatsapp ${ }^{\circledR}$. As palestras foram promovidas em tempo real através de Lives no YouTube ${ }^{\circledR}$ e disponibilizadas pelo canal do evento - Ciclo de Seminários em Química dos Diversos Saberes - YouTube. Dentre as palestras de maior alcance e visualização pelos participantes inscritos e ouvintes foram as denominadas "Maconha medicinal: uma contribuição da utilização do óleo da cannabis pelo Coletivo Mães Independentes do estado de Pernambuco" e "Fármacos utilizados na Covid-19: mecanismos e ações". Estas palestras tiveram em torno de 505 visualizações e 403, respectivamente, durante o momento da apresentação. Esses dados indicam o engajamento pela comunidade, sobretudo, pela relevância desses temas no contexto social, ademais as apresentações obtiveram grande sucesso em suas mensagens e diversificada interação.

Revista Extensão \& Cidadania, v. 9, n. 16, p.123-135, jul./dez. 2021.

ISSN 2319-0566 DOI: 10.22481/recuesb.v9i16.9049 
Dessa forma, a utilização de recursos tecnológicos digitais possibilitou expandir o alcance do evento, criando-se métodos oportunos de divulgar e levar o conhecimento e os diversos saberes, incluindo a química, em todo o território nacional. O perfil do público alcançado foi de acordo com o apresentado na Figura 1.

\section{Figura 1 - Relação do perfil do grau de formação dos participantes inscritos no Projeto}

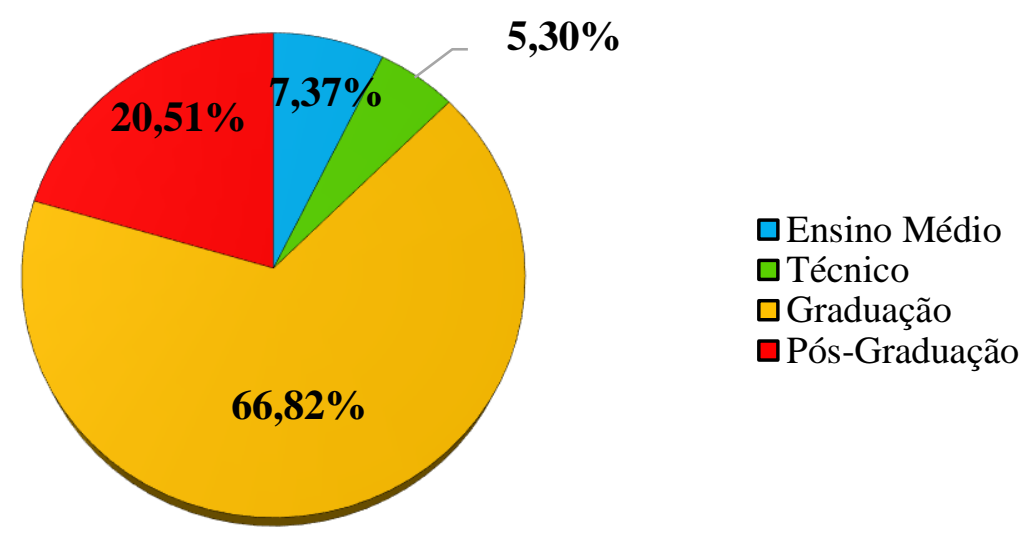

Fonte: Elaborado pelos autores (2021).

O projeto obteve 429 inscritos no site e mais 25 ouvintes cadastrados, logo, pode-se observar que $66,82 \%$ dos inscritos são discentes de graduação e/ou já possuem uma graduação, seguido com a participação de $20,51 \%$ de participantes que possuem ou estão em pósgraduação. Ademais, é importante avaliar a presença de participantes que estão no ensino médio e os que possuem ensino técnico, ambos somam 12,67\% dos inscritos.

O acompanhamento da presença nas atividades tornou possível avaliar a frequência dos participantes cadastrados conforme demonstrado na Figura 2. É perceptível um engajamento exponencial do público em meados de setembro e obtendo-se seu auge de inscritos no início de outubro.

Revista Extensão \& Cidadania, v. 9, n. 16, p.123-135, jul./dez. 2021.

ISSN 2319-0566 DOI: 10.22481/recuesb.v9i16.9049 
Figura 2 - Progressão de participantes inscritos no decorrer do período de inscrição

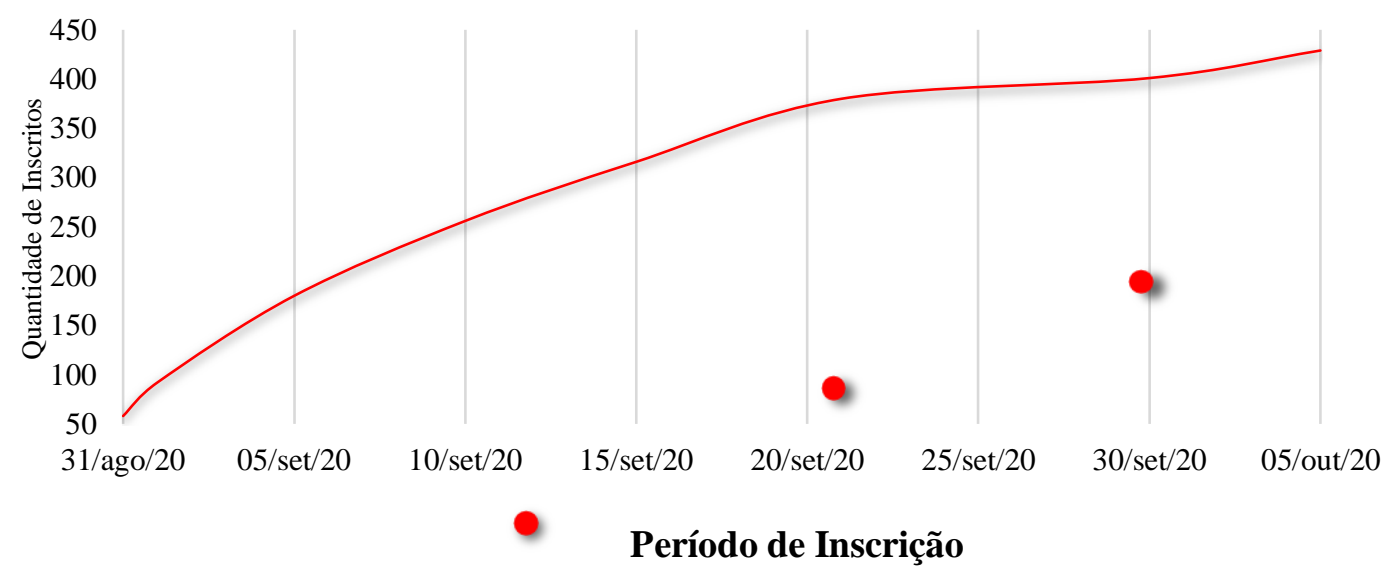

Fonte: Elaborado pelos autores (2021).

Assim, fazendo-se uma análise comparativa com os perfis dos ouvintes, na Figura 3 pode-se analisar as principais áreas do conhecimento do público-alvo inscrito.

Figura 3 - Principais áreas do conhecimento dos participantes inscritos

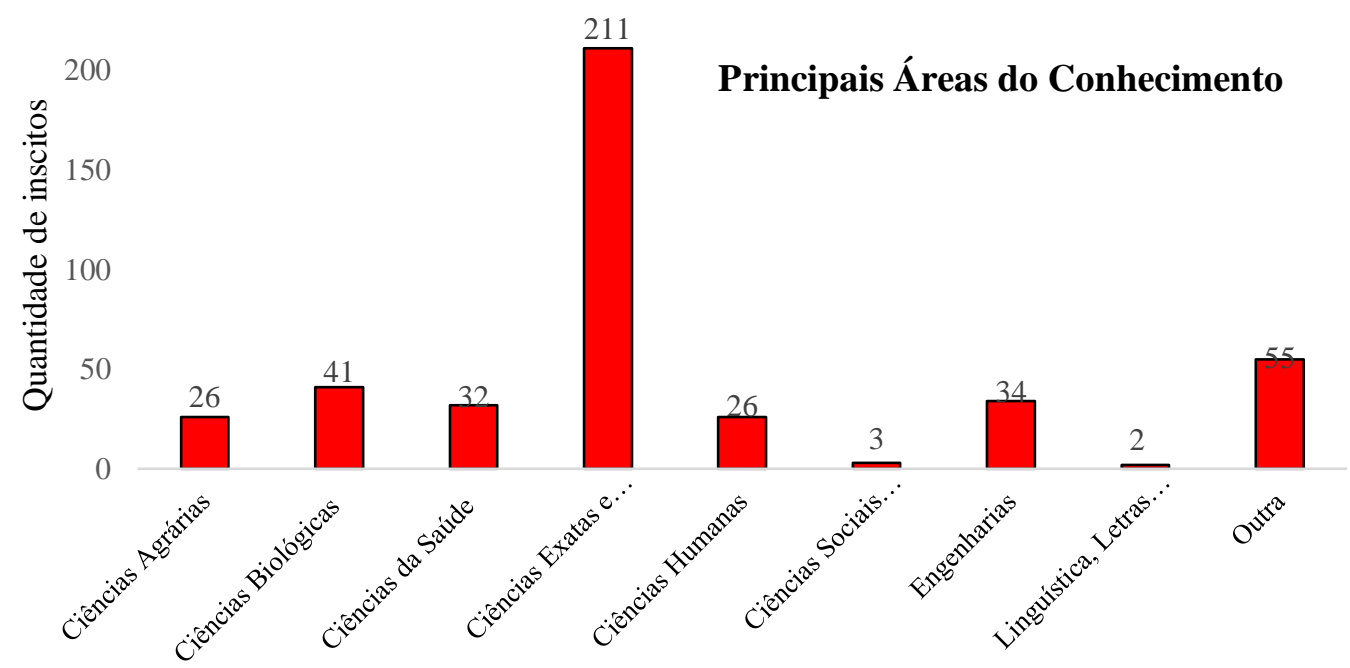

Fonte: Elaborado pelos autores (2021).

Revista Extensão \& Cidadania, v. 9, n. 16, p.123-135, jul./dez. 2021.

ISSN 2319-0566 DOI: 10.22481/recuesb.v9i16.9049 
Nota-se que 46,65\% dos participantes são da área das Ciências Exatas e da Terra. Contudo, os inscritos abrangeram diversas áreas do conhecimento, o que demostra o alcance do caráter interdisciplinar que o Ciclo de Seminários visou promover. A lista do curso com a formação dos participantes em diferentes segmentos é demonstrada na Figura 4.

\section{Figura 4 - Subáreas dos participantes de acordo com as inscrições}

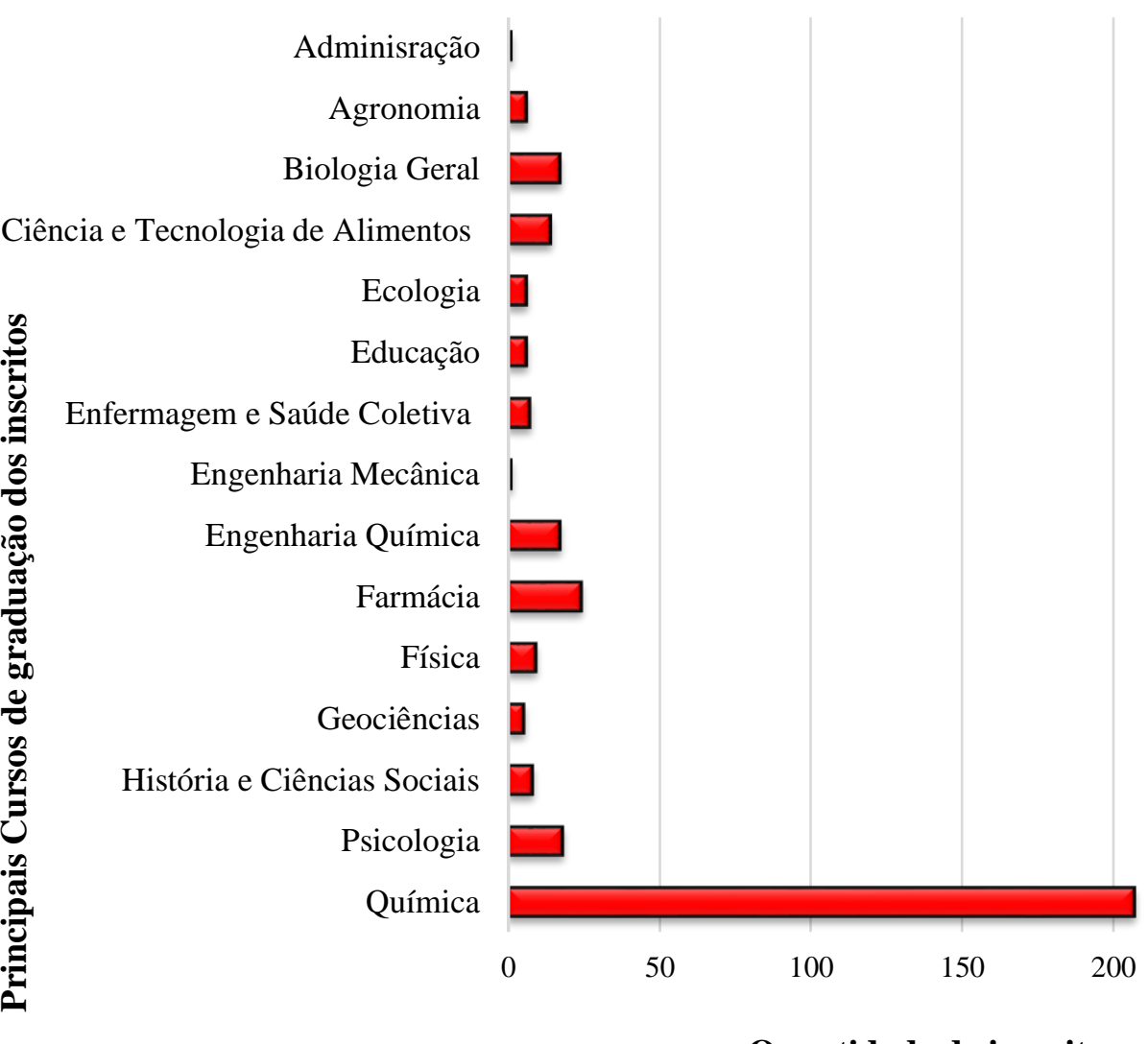

Fonte: Elaborado pelos autores (2021).

Discentes de graduação em Química correspondem a 45,59\% dos participantes no Ciclo de Seminários, avaliando-se o engajamento no decorrer do projeto, pode-se evidenciar uma ampla participação externa à universidade. Em torno de 98,23\% dos inscritos foram participantes em território brasileiro e 1,77\% corresponderam a participantes oriundos de outras nações, sendo elas, Suíça, Estados Unidos, Colômbia e Argentina.

Revista Extensão \& Cidadania, v. 9, n. 16, p.123-135, jul./dez. 2021.

ISSN 2319-0566 DOI: 10.22481/recuesb.v9i16.9049 
Durante a realização dos seminários, os participantes puderam interagir com os palestrantes e mediadores no intuito de tirar dúvidas e emitir sugestões. A Figura 5 apresenta a discriminação do público em função de ser externo e interno à UESB.

\section{Figura 5 - Discriminação de público-alvo interno e inscritos externos}

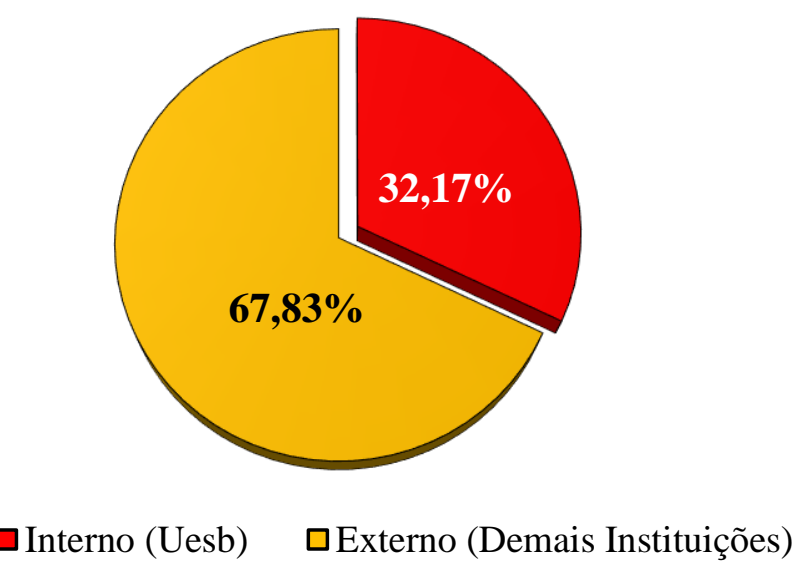

Fonte: Elaborado pelos autores (2021).

Em cada palestra, foi enviado aos participantes um questionário para avaliação do Projeto no intuito de identificar perspectivas para os próximos projetos de extensão que se darão de forma remota e/ou presencial. Entre as questões, perguntava-se uma nota para cada noite de palestras, obtendo-se uma média geral de 9,77 numa escala de 0 a 10, além de sugestões para uma maior duração do período do Projeto de Extensão.

De acordo com Oliveira et al., (2008), um projeto de extensão é um caminho de ação de uma universidade junto à comunidade, disponibilizando ao público o conhecimento adquirido com o ensino e a pesquisa desenvolvidos, e é um dos pilares de sustentação de instituições educativas. Dessa forma, o I Ciclo de Seminários Química dos Diversos Saberes contribuiu pelos resultados alcançados com o tripé que fundamenta construção dos variados saberes no âmbito científico e evidenciou o papel da química nas diversas áreas do conhecimento, inclusive, sua função no combate ao coronavírus (SARS-CoV-2).

Revista Extensão \& Cidadania, v. 9, n. 16, p.123-135, jul./dez. 2021.

ISSN 2319-0566 DOI: 10.22481/recuesb.v9i16.9049 
A extensão universitária funciona como uma via de duas mãos, possibilita a formação do profissional a se capacitar junto à comunidade como um recinto privilegiado de produção de conhecimento, que contribui para superar as diversidades e desigualdades sociais (CUNHA; LOPES, 2017).

Sendo assim, o Projeto de Extensão como alternativa remota da universidade em tempos de pandemia promoveu maior visibilidade do trabalho acadêmico e apresentou-se como oportunidade viável de se realizar palestras com profissionais de diferentes lugares do Brasil e de outros países. Nesse sentido, podendo-se transmitir informações e o despertar do interesse dos participantes ao visualizar os diversos saberes da química e suas contribuições para a sociedade civil e acadêmica. A experiência adquirida pelos membros da comissão organizadora servirá como base para a realização de novos projetos extensionistas.

\section{Conclusão}

O Projeto de Extensão "I Ciclo de Seminários de Química dos Diversos Saberes" demonstrou que, apesar da suspensão das atividades presenciais, foi possível realizar o contato da Universidade com a comunidade externa. $\mathrm{O}$ uso de ferramentas digitais permitiu alcançar pessoas do país e exterior, tendo alcance de estudantes e profissionais do ensino básico à pósgraduação e de diversas áreas de conhecimento. Logo, o Projeto demonstrou-se relevante no contexto social, sendo viável e interessante a sua realização em outras vezes de modo remoto. Como perspectivas, há possibilidade de tornar o evento de carácter anual, com subeventos sazonais, capaz de integrar a Química com outros segmentos da área de Ciências Exatas.

\section{Referências}

ARROYO, Daniela Munerato Piccolo; ROCHA, Maria Silva Pinto de Moura Librandi. Metaavaliação de uma extensão universitária: estudo de caso. Avaliação, Campinas; Sorocaba, v. 15, n. 2, p. 131-157, jul. 2010.

BRASIL. Ministério da Saúde. Ministério da Saúde declara transmissão comunitária nacional. [S. l.], 2020a. Disponível em: https://www.gov.br/saude/ptbr/assuntos/noticias/ministerio-da-saude-declara-transmissao-comunitaria-nacional. Acesso em: 5 maio 2021.

Revista Extensão \& Cidadania, v. 9, n. 16, p.123-135, jul./dez. 2021.

ISSN 2319-0566 DOI: 10.22481/recuesb.v9i16.9049 
BRASIL. Ministério da Educação. Portaria no 343, de 17 de março de 2020. Dispõe sobre a substituição das aulas presenciais por aulas em meios digitais enquanto durar a situação de pandemia do Novo Coronavírus - COVID-19. [S. l.], 2020b. Disponível em:

https://www.in.gov.br/en/web/dou/-/portaria_-n-376-de-3-de-abril-de-2020- 251289119.

Acesso em: 10 maio 2021.

CIRÍACO, Klinger Teodoro et al. Ações de ensino, pesquisa e extensão e suas potencialidades à promoção de práticas para a educação das relações étnico-raciais. Brazilian Journal of Development, v. 6, n. 7, p. 43178-43200, 2020.

CUNHA, Joaci de S.; LOPES, Catarina. CEAS 50 anos: em tempos sombrios, tecemos esperança. Cadernos do CEAS: Revista Crítica de Humanidades, n. 241, p. 258-267, 2017.

DA SILVA, Márcia Regina Farias et al. Reflexões sobre as ações extensionistas e de pesquisa no combate à COVID-19 na universidade do estado do Rio Grande do Norte. Brazilian Journal of Health Review, v. 3, n. 2, p. 3622-3646, 2020.

NUNES, Ana Lucia de Paula Ferreira; DA CRUZ SILVA, Maria Batista. A extensão universitária no ensino superior e a sociedade. Mal-Estar e Sociedade, v. 4, n. 7, p. 119-133, 2011.

OLIVEIRA, Ana Cristina et al. Uso de serviços odontológicos por pacientes com síndrome de Down. Revista de Saúde Pública, v. 42, p. 693-699, 2008.

OMS. Organização Mundial da Saúde. Timeline of WHO's response to COVID-19. [S. l.], 2020. Disponível em: https://www.who.int/emergencies/diseases/novel-coronavirus2019/interactive-timeline. Acesso em: 10 maio 2021.

SOUSA, Ana Luiza Lima. A história da extensão universitária a partir de seus interlocutores. 1995. 365 f. Dissertação (Mestrado em Educação Escolar Brasileira) Faculdade de Educação, Universidade Federal de Goiás, Goiânia, 1995.

WOLFE, Nathan. The viral storm: the dawn of a new pandemic age. New York: Times Book, Henry Holt and Company, 2011.

Recebido: 10.05.2021

Aceito: 11.08.2021

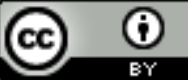

This work is licensed under a Creative Commons Attribution 4.0 International License.

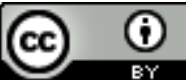

Este trabalho está licenciado com uma Licença Creative Commons - Atribuição 4.0

Internacional.

Revista Extensão \& Cidadania, v. 9, n. 16, p.123-135, jul./dez. 2021.

ISSN 2319-0566 DOI: 10.22481/recuesb.v9i16.9049 